\title{
Antileishmanial Activity of Niosomal Combination Forms of Tioxolone along with Benzoxonium Chloride against Leishmania tropica
}

\author{
Maryam Hakimi Parizi', Saeedeh Farajzadeh,*, Iraj Sharifi', Abbas Pardakhty ${ }^{3}$, Mohammad Hossein Daie Parizi", \\ Hamid Sharifi ${ }^{5}$, Ehsan Salarkia', Saeid Hassanzadeh ${ }^{6}$ \\ 'Leishmaniasis Research Center, Kerman University of Medical Sciences, Kerman, Iran; ${ }^{2}$ Department of Pediatric dermatology, Kerman University of \\ Medical Sciences, Kerman, Iran; ${ }^{P}$ Pharmaceutics Research Center, Neuropharmacology Institute, Kerman University of Medical Sciences, Kerman, \\ Iran; ${ }^{4}$ Department of Pediatrics, Kerman University of Medical Sciences, Kerman, Iran; ${ }^{5}$ HIVISTI Surveillance Research Center, and WHO \\ Collaborating Center for HIV Surveillance, Institute for Futures Studies in Health, Kerman University of Medical Sciences, Kerman, Iran; ${ }^{6}$ Department \\ of Pathobiology, Faculty of Veterinary Medicine, Shahid Bahonar University of Kerman, Kerman, Iran
}

\begin{abstract}
In this study, we carried out extensive in vitro studies on various concentrations of tioxolone along with benzoxonium chloride and their niosomal forms against Leishmania tropica. Niosomes were prepared by the hydration method and were evaluated for morphology, size, release study, and encapsulation efficiency. This study measured leishmanicidal activity against promastigote and amastigote, apoptosis and gene expression levels of free solution and niosomalencapsulated tioxolone along with benzoxonium chloride. Span/Tween 60 niosome had good physical stability and high encapsulation efficiency (more than 97\%). The release profile of the entrapped compound showed that a gradual release rate. The combination of niosomal forms on promastigote and amastigote were more effective than glucantime. Also, the niosomal form of this compound was significantly less toxic than glucantime $(P \leq 0.05)$. The flowcytometric analysis on niosomal form of drugs showed that higher number of early apoptotic event as the principal mode of action $(89.13 \%$ in $200 \mu \mathrm{g} / \mathrm{ml})$. Also, the niosomal compound increased the expression level of IL-12 and metacaspase genes and decreased the expression level of the IL-10 gene, which further confirming the immunomodulatory role as the mechanism of action. We observed the synergistic effects of these 2 drugs that induced the apoptotic pathways and also up regulation of an immunomodulatory role against as the main mode of action. Also, niosomal form of this combination was safe and demonstrated strong anti-leishmaniasis effects highlights further therapeutic approaches against anthroponotic cutaneous leishmaniasis in future planning.
\end{abstract}

Key words: Leishmania tropica, tioxolone, benzoxonium chloride, niosome

\section{INTRODUCTION}

Leishmaniasis, the third most important vector-borne diseases, caused by obligate intra-macrophage protozoa that is endemic in the tropics and sub-tropics area [1]. It is a complex disease with diverse clinical forms and among which, the cutaneous presentation, is the most common [2]. Conventional chemotherapy is the only effective measure against this disease. The first-choice compounds for the treatment of leishmaniasis includes pentavalent antimonials such as sodium sti-

- Received 7 January 2019, revised 9 March 2019, accepted 13 March 2019

*Corresponding author (s.farajzadeh97@gmail.com)

(c) 2019, Korean Society for Parasitology and Tropical Medicine

This is an Open Access article distributed under the terms of the Creative Commons Attribution Non-Commercial License (http://creativecommons.org/licenses/by-nc/4.0) which permits unrestricted non-commercial use, distribution, and reproduction in any

medium, provided the original work is properly cited. bogluconate (Pentostam), and meglumine antimoniate (Glucantime $\left.{ }^{\circledR}\right)$. Despite the recent advances, these chemotherapeutic measures have a number of important disadvantages such as severe side effects, the emergence of resistance, daily parenteral or weekly intralesional administration, and high cost [3]. Also, the advent of resistance and chronicity occurs in anthroponotic cutaneous leishmaniasis (ACL) due to Leishmania tropica more frequently than other Leishmania species. Therefore, development of an effective medication against the disease is very important [4]. Combination therapy can also have many benefits such as synergistic activity, reduced dosage and duration of treatment, thereby increasing compliance; reduction of the cost and adverse effects of therapy, as well as reducing the risk of resistance.

Currently, numerous investigations have been carried out to find a low-risk, effective, inexpensive and easy-to-use drug. 

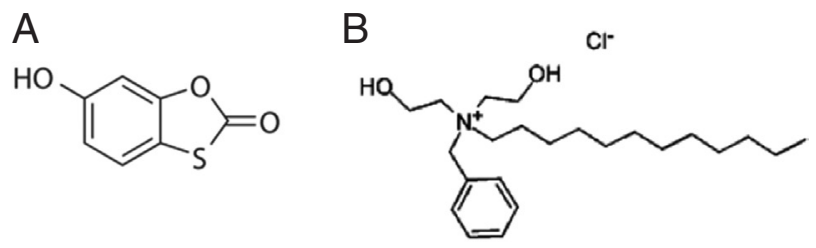

Fig. 1. Chemical structures of (A) 6-hydroxy-1, 3-benzoxathol2-one (tioxolone) and (B) benzyldodecylbis (2-hydroxyetyl) ammonium chloride (benzoxonium chloride).

Meanwhile, the new pharmaceutical formulations such as liposome and niosome, especially with topical application, appear to be promising because surrounding tissues are not affected by the drug and loss of drug does not happen due to localization, leading to enhance maximum efficacy of the medication. Niosomes are the best carriers and are vesicles composed of non-ionic surfactants, which are biodegradable, more stable and inexpensive [5].

In previous study we reported the therapeutic effect of topical application that was named Thio-Ben. This drug was a mixture of tioxolone and benzoxonium chloride. Their clinical trial showed that the topical use of Thio-Ben was as effective as the intralesional treatment with glucantime [6]. Tioxolone $\left(\mathrm{C}_{7} \mathrm{H}_{4} \mathrm{O}_{3} \mathrm{~S}\right)$ (Fig. 1A), have been used for local treatment of acne and psoriasis vulgaris and also known as anti-fungal, anti-bacterial, anti-inflammatory and anti-tumorigenic effects $[7,8]$. Also, benzoxonium chloride $\left(\mathrm{C}_{23} \mathrm{H}_{42} \mathrm{ClNO}_{2}\right)$ (Fig. 1B) belongs to quaternary ammonium compounds of anti-infective agents that are used as anti-septic drugs and for disinfecting the mucus membrane, skin surface, and medical instruments. Benzoxonium chloride is also effective against bacteria, certain protozoa, yeasts and non-spore forming organisms [9]. Since the niosomal formulation of combine these 2 drugs may potentially be more effective on $L$. tropica, therefore, in this study, we carried out extensive studies in in vitro models using various concentrations of tioxolone along with benzoxonium chloride and its niosomal forms.

\section{MATERIALS AND METHODS}

\section{Preparation and characterization of niosomes}

Niosomal vesicles were prepared by the hydration method as reported previously [10]. Briefly, the nonionic surfactants (Span 20, 40, 60, 80 and Tween 20, 40, 60, 80) and cholesterol were dissolved in chloroform and mixed at different molar ratios $(7: 3,6: 4$, and 8:2) in a round-bottom flask. Tioxolone $(5,000$ $\mu \mathrm{g} / \mathrm{ml}$ ) was dissolved in $100 \mathrm{ml}$ chloroform and $5 \mathrm{ml}$ added in the flasks. The solvent was evaporated using a rotary evaporator (Büchi, Flawil, Switzerland) at $180 \mathrm{rpm}$ and $70^{\circ} \mathrm{C}$ for $15 \mathrm{~min}$ and a thin layer of lipid film formed on the wall of the flask.

The lipid film was hydrated with $5 \mathrm{ml}$ of $100 \mathrm{ml}$ deionized water containing $3,000 \mu \mathrm{g} / \mathrm{ml}$ of benzoxonium chloride to the flask at $70^{\circ} \mathrm{C}$ for $30 \mathrm{~min}$. The resulting niosomal suspensions were maintained over night at room temperature for further experimentations. The morphology of vesicles was observed using light microscopy (Zeiss, Oberkochen, Germany). Size of vesicles was evaluated by measuring their dynamic light scattering with Master Sizer 2000 E (Malvern Instruments, Malvern, UK). Also, physical stability of niosomes was determined by size variations over 3 days, 1, 3, and 6 months after production.

Release profiles of entrapped drugs were determined by dialysis method [11] in selected formulations using the dialysis bag (cellulose acetate membrane, Sigma-Aldrich, Steinheim, Germany) at $37^{\circ} \mathrm{C}$ for certain time intervals $(0,15,30,60,90$, $120,150,180,210,240 \mathrm{~min})$. The drugs concentrations in the samples were measured using the spectrophotometric method at $287.9 \mathrm{~nm}$ for tioxolone and at $208 \mathrm{~nm}$ for benzoxonium chloride. Also, encapsulation efficiency was performed by dialysis method and calculated the entrapped drug [12] as per the following equation:

$\%$ Encapsulation efficiency $=\frac{\text { Total drug }- \text { free non entrapped drug }}{\text { Total drug }} \times 100$

\section{Cells and parasite}

Standard strain of L. tropica (MHOM/IR/2002/Mash2) was prepared from the Leishmaniasis Research Center (Kerman, Iran) and cultured in RPMI-1640, $1 \mu$ penicillin-streptomycin (10,000 IU/ml), 15\% heat-inactivated fetal bovine serum (FBS) and incubated at $25^{\circ} \mathrm{C} \pm 1^{\circ} \mathrm{C}$. Murine macrophage cells J774 A.1 ATCC ${ }^{\circledR T I B-} 67^{\mathrm{TM}}$ were purchased from the Pasteur Institute of Iran and cultured in DMEM, $1 \mu$ penicillin-streptomycin $(10,000 \mathrm{IU} / \mathrm{ml})$ and $15 \%$ inactivated $\mathrm{FBS}$ at $37^{\circ} \mathrm{C}$ and $5 \% \mathrm{CO}_{2}$.

\section{The viability rate of macrophages and serial dilutions}

At first, the cytotoxicity of the tioxolone ( $\mathrm{T}$ ) along with benzoxonium chloride (B) and their selected niosomal forms (NT and NB) were carried out separately by MTT assay on J774 A.1. Then once the concentrations of the $\mathrm{T}$ drug were fixed and the concentration of B was increased. Again, we kept the concentrations of $\mathrm{B}$ constant and increased the concentration of $\mathrm{T}$ 
drug. In the niosomal combination of $\mathrm{NT}$ and $\mathrm{NB}$, at first, diligence was done based on NT and then serial dilutions were based on NB.

\section{Antipromastigote assay}

L. tropica $\left(10^{5}\right.$ parasites $\left./ \mathrm{ml}\right)$ in the logarithmic growth phase were incubated in RPMI-1640 medium supplemented with $10 \%$ FBS in the presence of several concentrations of tioxolone along with benzoxonium chloride and its niosomal forms as triplicate in 96-well plates at $25^{\circ} \mathrm{C} \pm 1^{\circ} \mathrm{C}$ for $48 \mathrm{hr}$. Simultaneously, meglumine antimoniate (glucantime) and medium with no drugs were used as positive and negative control, respectively. Leishmanicidal activity of tioxolone along with benzoxonium chloride and niosamal forms of this combination at the promastigote stage of L. tropica were measured by MTT analysis.

\section{Antiamastigote assay}

Attached macrophages were infected with L. tropica promastigotes (stationary growth phase) at a parasite/macrophage ratio of 10:1 and incubated at $37^{\circ} \mathrm{C}$ and $5 \% \mathrm{CO}_{2}$ for $24 \mathrm{hr}$. Then, the macrophages containing parasites were treated with serial dilutions of all drugs and control in triplicates, were incubated at $37^{\circ} \mathrm{C}$ and $5 \% \mathrm{CO}_{2}$ for $48 \mathrm{hr}$. Cells were then fixed with 100\% methanol fixative, stained with Wright Giemsa for 15 min. The average number of amastigotes in 100 macrophages was determined by examining 3 slides for each treatment by direct microscopy and the results were compared to controls. The survival index was determined by multiplying the number of infected cells by the mean number of amastigotes per cell and the results were used to establish a proportion in relation to the control.

\section{Determination of apoptosis}

Apoptotic and necrotic cell events were studied by PE Annexin $\mathrm{V}$ and 7-Amino Actinomycin D (7-AAD) with PE Annexin V Apoptosis Detection Kit I (BD Pharmingen ${ }^{\mathrm{TM}}$, BD Biosciences, San Jose, California, USA). The L. tropica promastigotes $\left(1 \times 10^{6}\right)$ were treated with the desired concentrations of selected combination drugs and incubated at $25^{\circ} \mathrm{C}$ for $48 \mathrm{hr}$. Then, promastigotes were washed in cold phosphate-buffered saline (PBS) twice, suspended in $1 \mathrm{X}$ binding buffer and were added $5 \mu \mathrm{l}$ of PE Annexin V and $5 \mu \mathrm{l}$ 7-AAD in the dark for 15 $\mathrm{min}$. The samples were analyzed by flowcytometry (BD FACSCalibur $^{\mathrm{TM}}$, San Jose, California, USA).

\section{RNA isolation and analysis}

RNA was extracted using the RNeasy Mini Kit (Qiagen, Chatsworth, California, USA) according to the manufacturer's instructions at various concentrations of effective drug combination and untreated control. The cDNA was synthesized by a first-strand cDNA Synthesis Kit (Takara Bio, Inc., Shiga, Japan). Glyceraldehyde 3-phosphate dehydrogenase (GAPDH) was used as reference for gene expression of IL-12 and IL-10 in murine macrophage cells (J774 A. 1) and RPS18 Ribosomal protein (S18) for gene expression of metacaspase in promastigote and they were detected by quantitative real-time PCR (q-PCR) assay $[13,14]$. The $\Delta \mathrm{CT}$ was measured by means of the following formula: $[\Delta \mathrm{CT}=\mathrm{CT}$ (target) - CT (reference) $]$. Gene expression level was specified by the $2^{-\Delta \mathrm{Ct}}$ methods. Moreover, fold increase (FI) was measured through the comparative threshold method $\left(2^{-\Delta \Delta C T}\right)$.

\section{Statistical analyses}

Data were analyzed by one-way analysis of variance (ANOVA), and differences between groups were assessed using Bonferroni test in the SPSS software version 20 (Chicago, Illinois, USA). Results were considered significant at $P \leq 0.05$. The graphs were designed using GRAPHPAD PRISM 6 (GraphPad Software Inc, San Diego, California, USA).

\section{RESULTS}

\section{Characterization of niosomes}

The morphology of prepared niosomes and their particle

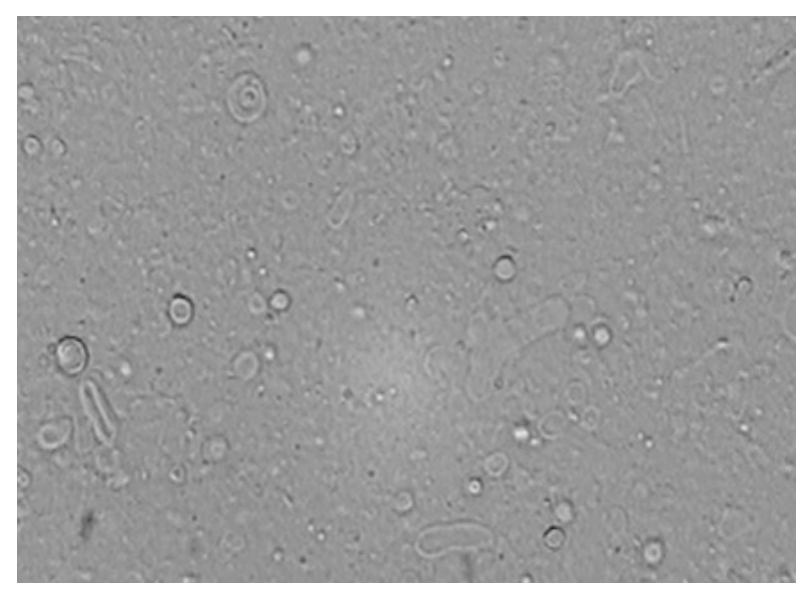

Fig. 2. The light microscopic picture of niosomal forms of tioxolone along with benzoxonium chloride ( $\times 100$ magnification) prepared by film hydration method. 
A

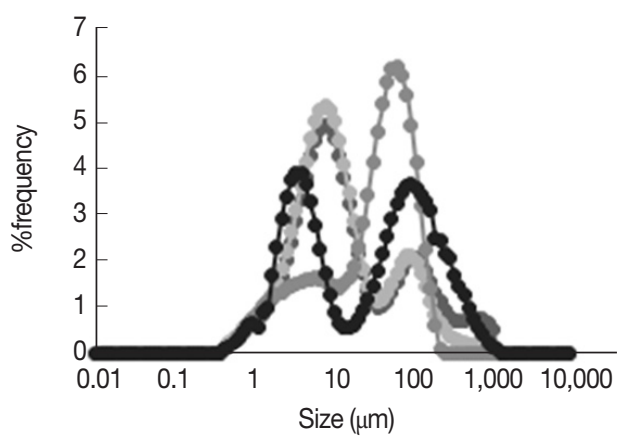

B

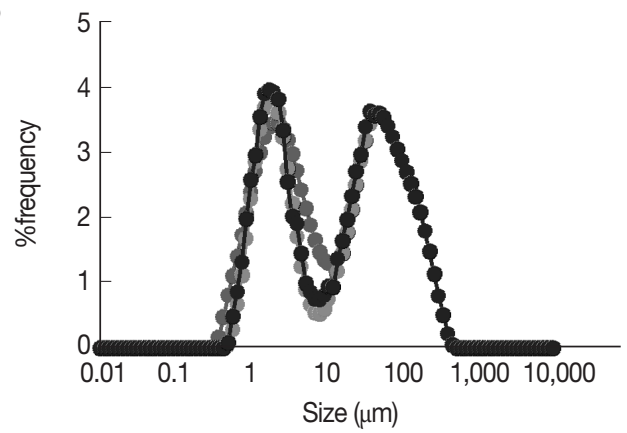

Fig. 3. The particle size distribution graph by frequency of (A) Span Tween 40 (6:4 m.r., NTB $)$ and (B) Span Tween 60 (6:4 m.r., NTB2) at 3 days, 1,3 , and 6 months.

Table 1. Encapsulation efficiency percentage (\%EE) of niosomal tioxolone along with benzoxonium chloride formulation

\begin{tabular}{lcccccc}
\hline Active ingredient & $\lambda \max (\mathrm{nm})$ & Absorbance & $\begin{array}{c}\text { Concentration } \\
(\mu \mathrm{g} / \mathrm{ml})\end{array}$ & $\begin{array}{c}\text { Amount } \\
\text { (Dialysate solution) }\end{array}$ & $\begin{array}{c}\text { Total } \\
(\mu \mathrm{g} / \mathrm{ml})\end{array}$ & $\% \mathrm{EE}$ \\
\hline Tioxolone & 278 & 0.15 & 7.04 & 105.6 & 5,000 & 97.88 \\
Benzoxonium chloride & 208 & 0.17 & 5.26 & 78.9 & 3,000 & 97.37 \\
\hline
\end{tabular}

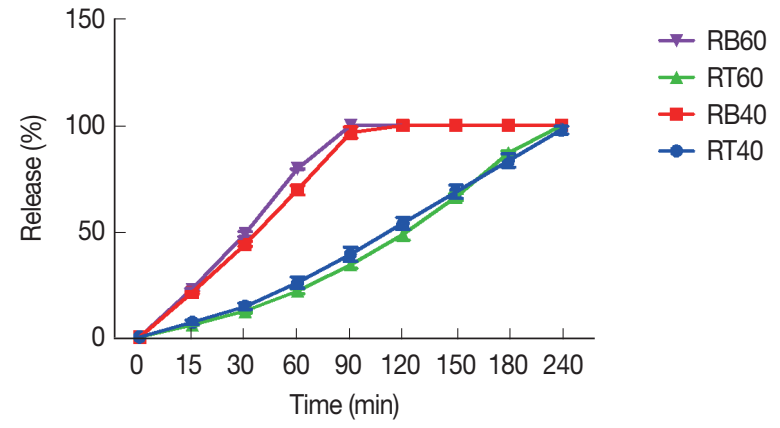

Fig. 4. The released amount of niosomal of tioxolone $(\%, \mathrm{RT})$ and benzoxonium chloride $(\%, \mathrm{RB})$ from the selected formulations at different time intervals (mean $\pm S D, n=3$ ).

size distribution showed that, the best formulations were Span/ Tween 40 (ST40, 6:4 molar ratio, $\mathrm{NTB}_{1}$ ) and Span/Tween 60 (ST60, 6:4 m.r, $\mathrm{NTB}_{2}$ ) (Figs. 2,3). Size analysis of 2 formulations showed 2 log-normal particle size distribution curves after 3 days but only $\mathrm{NTB}_{2}$ had good physical stability, as depicted in their size distribution curves during 1, 3, and 6 months (Fig. 3). High encapsulation efficiency (more than 97\%) was calculated for $\mathrm{NTB}_{1}$ and $\mathrm{NTB}_{2}$ (Table 1). The release profile of niosomal forms of entrapped materials showed that the release rate of tioxolone was a mild gradient but benzoxonium chloride was completely released at $90 \mathrm{~min}$. Both formulations $\left(\mathrm{NTB}_{1}\right.$ and $\left.\mathrm{NTB}_{2}\right)$ showed a similar release rate (Fig. 4).

\section{The viability rate of macrophages}

The viability rates of macrophages after treatment with com- bination of tioxolone $(\mathrm{T})$ along with benzoxonium chloride (B) in comparison with untreated control were showed a significant difference $(P<0.001)$ (Fig. $5 \mathrm{~A})$. Also, the viability rate of macrophages is reduced by increasing the concentration of each drug (T or B). Whereas, these rate in combinations of niosomes were higher than glucantime $(P \leq 0.05)$ (Fig. $5 \mathrm{~B})$. The viability rate of macrophages at $12.5,25,50,100$, and 150 $\mu \mathrm{g} / \mathrm{ml}$ concentrations of glucantime were $87.46 \pm 0.15,77.96 \pm$ $0.35,70.50 \pm 0.50,68.20 \pm 0.40$, and $67.00 \pm 0.20$, respectively.

\section{Antileishmanicidal activity on promastigote}

The percentage of inhibition rate of $L$. tropica promastigotes treated with various concentrations of tioxolone (T) along with benzoxonium chloride (B) in comparison with $\mathrm{T}$ alone showed a dose-dependent response, as presented in Fig. 6A. Also, the inhibition rate of promastigotes treated with various concentrations $(12.5,25,50,100$, and $150 \mu \mathrm{g} / \mathrm{ml})$ of glucantime were $19.86 \pm 1.27,24.03 \pm 0.35,29.76 \pm 1.16,35.80 \pm$ 0.40 , and $39.66 \pm 0.41$, respectively, that in comparison with these rates in tioxolone along with benzoxonium chloride were significantly lower $(P \leq 0.05)$.

The inhibitory rates of $L$. tropica promastigotes treated with various concentrations of the combinations of niosomes compared with glucantime, as presented in Fig. $6 \mathrm{~B}$, which indicates that their inhibitory rates were significantly higher than glucantime $(P \leq 0.05)$. 

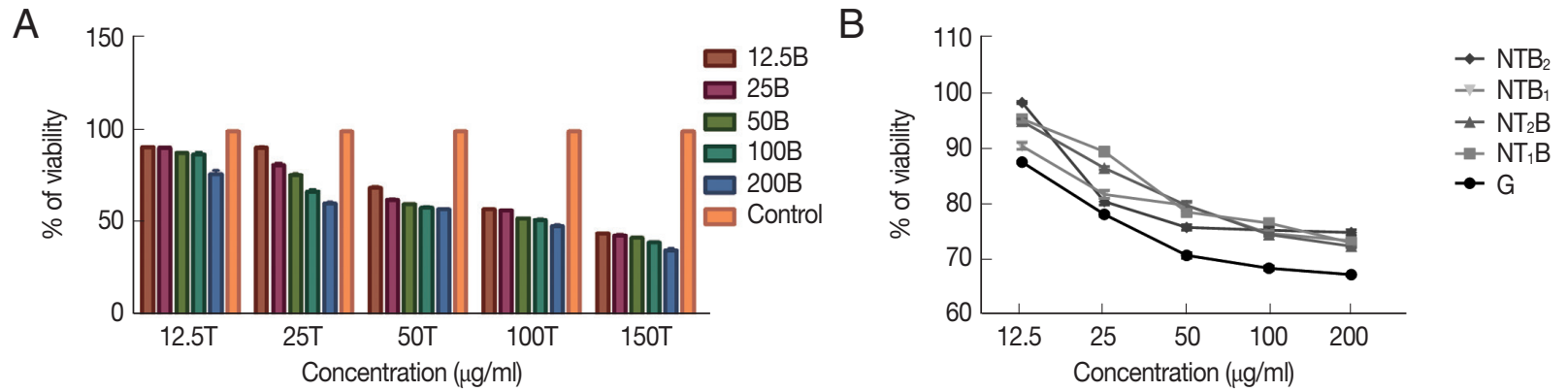

Fig. 5. The viability of $J 774$ A.1 cells in the presence of various concentrations of combination of $(A)$ tioxolone $(T)$ along with benzoxonium chloride (B) in comparison with untreated control; (B) niosomes (NTB) in comparison with glucantime (G) after $48 \mathrm{hr}$ incubation. Bars represent the mean \pm standard deviation of viability rates $\left(N T_{1} B\right.$ and $N T_{2} B$ : serial dilutions were based on $N B ; N_{1} B_{1}$ and $N B_{2}$ : serial dilutions were based on NT).
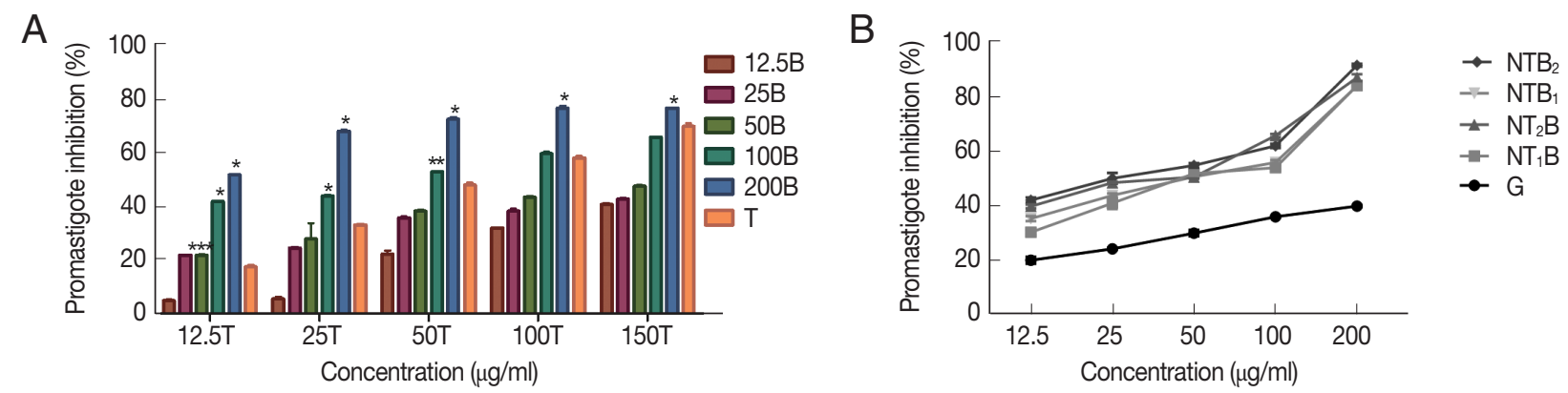

Fig. 6. The inhibitory rates of $L$. tropica promastigotes treated with various concentrations of (A) tioxolone $(T)$ along with benzoxonium chloride (B) in comparison with the T alone; (B) the combinations of niosomes in comparison with glucantime (G) after $48 \mathrm{hr}$ incubation. Bars represent the mean $\pm \mathrm{SD}$ of inhibitory rates $\left({ }^{*} P<0.001,{ }^{* *} P<0.01,{ }^{* \star} P<0.05\right.$ and $N T_{1} B$ and $N T_{2} B$ : serial dilutions were based on $\mathrm{NB}$; NTB 1 and $\mathrm{NTB}_{2}$ : serial dilutions were based on NT).

Table 2. Comparative evaluation of the effect of tioxolone $(T, 150,100,50,25,12.5 \mu \mathrm{g} / \mathrm{ml})$ combined with various concentrations of benzoxonium chloride (B, 200, 100, 50, 25, $12.5 \mathrm{\mu g} / \mathrm{ml})$ with untreated control on intramacrophage amastigotes of $L$. tropica after $48 \mathrm{hr}$ incubation $(P \leq 0.05)$

\begin{tabular}{|c|c|c|c|c|c|c|c|c|c|c|}
\hline \multirow{2}{*}{$\begin{array}{l}\text { Concentration } \\
(\mu \mathrm{g} / \mathrm{ml})\end{array}$} & \multicolumn{2}{|c|}{$12.5 \mathrm{~B}$} & \multicolumn{2}{|c|}{$25 B$} & \multicolumn{2}{|c|}{$50 B$} & \multicolumn{2}{|c|}{$100 \mathrm{~B}$} & \multicolumn{2}{|c|}{$200 B$} \\
\hline & $\begin{array}{l}\text { No. of } \\
\text { amastigotes }\end{array}$ & $P$-value & $\begin{array}{c}\text { No. of } \\
\text { amastigotes }\end{array}$ & $P$-value & $\begin{array}{c}\text { No. of } \\
\text { amastigotes }\end{array}$ & $P$-value & $\begin{array}{c}\text { No. of } \\
\text { amastigotes }\end{array}$ & $P$-value & $\begin{array}{c}\text { No. of } \\
\text { amastigotes }\end{array}$ & $P$-value \\
\hline 0.0 (Control) & $60.71 \pm 1.46$ & NR & $60.71 \pm 1.46$ & NR & $60.71 \pm 1.46$ & $N R$ & $60.71 \pm 1.46$ & NR & $60.71 \pm 1.46$ & $N R$ \\
\hline $12.5 \mathrm{~T}$ & $43.70 \pm 0.60$ & 0.001 & $40.60 \pm 0.70$ & 0.001 & $36.20 \pm 0.70$ & 0.001 & $32.16 \pm 0.70$ & 0.001 & $29.26 \pm 0.25$ & 0.001 \\
\hline $25 \mathrm{~T}$ & $37.56 \pm 0.55$ & 0.001 & $35.50 \pm 0.30$ & 0.001 & $33.16 \pm 0.40$ & 0.001 & $29.30 \pm 0.85$ & 0.001 & $24.33 \pm 0.65$ & 0.001 \\
\hline $50 \mathrm{~T}$ & $32.33 \pm 0.25$ & 0.001 & $30.26 \pm 0.60$ & 0.001 & $27.40 \pm 0.30$ & 0.001 & $25.43 \pm 0.35$ & 0.001 & $22.10 \pm 0.30$ & 0.001 \\
\hline $100 \mathrm{~T}$ & $30.30 \pm 0.50$ & 0.001 & $29.40 \pm 0.50$ & 0.001 & $25.93 \pm 0.45$ & 0.001 & $22.70 \pm 0.30$ & 0.001 & $20.66 \pm 0.32$ & 0.001 \\
\hline $150 \mathrm{~T}$ & $29.90 \pm 0.34$ & 0.001 & $29.00 \pm 0.50$ & 0.001 & $23.70 \pm 0.20$ & 0.001 & $21.46 \pm 0.41$ & 0.001 & $19.33 \pm 0.32$ & 0.001 \\
\hline
\end{tabular}

Data represent the mean value \pm SD.

NR, Not related.

\section{Antileishmanicidal activity on amastigote}

The average number of amastigotes in 100 macrophages at various concentrations of $\mathrm{T}$ with $\mathrm{B}$ is shown in Table 1, which represents that with increasing concentration of each drug, the number of amastigotes was decreased. This combination of $\mathrm{T} 150 \mu \mathrm{g} / \mathrm{ml}$ and B200 $\mu \mathrm{g} / \mathrm{ml}$ showed the least number of amastigotes $(19.33 \pm 0.34)$. Also, in niosomal formulations, with increasing concentration, the number of amastigotes were decreased, so that, the least number of amastigote (10.51 \pm 0.43$)$ belongs to the highest concentration of $\mathrm{NTB}_{2}$ formulation $(200 \mu \mathrm{g} / \mathrm{ml})$.

Various concentrations of the drugs ( $\mathrm{T}$ along with B or NTB) 
Table 3. Comparative evaluation of various concentrations of the combination niosomes and glucantime with untreated control on intramacrophage amastigotes of $L$. tropica after $48 \mathrm{hr}$ incubation $(P \leq 0.05)\left(\mathrm{NT}_{1} \mathrm{~B}\right.$ and $\mathrm{NT}_{2} \mathrm{~B}$ : serial dilutions were based on $\mathrm{NB}$; NTB 1 and $\mathrm{NTB}_{2}$ : serial dilutions were based on NT)

\begin{tabular}{|c|c|c|c|c|c|c|c|c|c|c|}
\hline \multirow{2}{*}{$\begin{array}{l}\text { Concentration } \\
(\mu \mathrm{g} / \mathrm{ml})\end{array}$} & \multicolumn{2}{|c|}{12.5} & \multicolumn{2}{|l|}{25} & \multicolumn{2}{|l|}{50} & \multicolumn{2}{|l|}{100} & \multicolumn{2}{|c|}{200} \\
\hline & $\begin{array}{c}\text { No. of } \\
\text { amastigote }\end{array}$ & $P$-value & $\begin{array}{c}\text { No. of } \\
\text { amastigote }\end{array}$ & $P$-value & $\begin{array}{c}\text { No. of } \\
\text { amastigote }\end{array}$ & $P$-value & $\begin{array}{c}\text { No. of } \\
\text { amastigote }\end{array}$ & $P$-value & $\begin{array}{c}\text { No. of } \\
\text { amastigote }\end{array}$ & $P$-value \\
\hline 0.00 (Control) & $60.71 \pm 1.46$ & $N R$ & $60.71 \pm 1.46$ & NR & $60.71 \pm 1.46$ & $N R$ & $60.71 \pm 1.46$ & NR & $60.71 \pm 1.46$ & NR \\
\hline Glucantime & $54.20 \pm 1.06$ & 0.013 & $41.86 \pm 1.02$ & 0.001 & $34.46 \pm 2.05$ & 0.001 & $31.46 \pm 1.91$ & 0.001 & $22.96 \pm 2.62$ & 0.001 \\
\hline $\mathrm{NBT}_{1}$ & $34.60 \pm 0.34$ & 0.001 & $22.67 \pm 0.57$ & 0.001 & $19.19 \pm 0.68$ & 0.001 & $18.49 \pm 0.34$ & 0.001 & $14.17 \pm 0.19$ & 0.001 \\
\hline $\mathrm{NBT}_{2}$ & $33.44 \pm 0.71$ & 0.001 & $21.71 \pm 0.75$ & 0.001 & $19.81 \pm 0.54$ & 0.001 & $16.27 \pm 1.14$ & 0.001 & $10.92 \pm 0.39$ & 0.001 \\
\hline $\mathrm{NTB}_{1}$ & $35.55 \pm 1.28$ & 0.001 & $23.85 \pm 0.68$ & 0.001 & $23.29 \pm 0.60$ & 0.001 & $22.12 \pm 0.89$ & 0.001 & $12.26 \pm 0.44$ & 0.001 \\
\hline $\mathrm{NTB}_{2}$ & $25.55 \pm 1.26$ & 0.001 & $17.71 \pm 0.58$ & 0.001 & $16.07 \pm 0.46$ & 0.001 & $13.54 \pm 1.12$ & 0.001 & $10.51 \pm 0.43$ & 0.001 \\
\hline
\end{tabular}
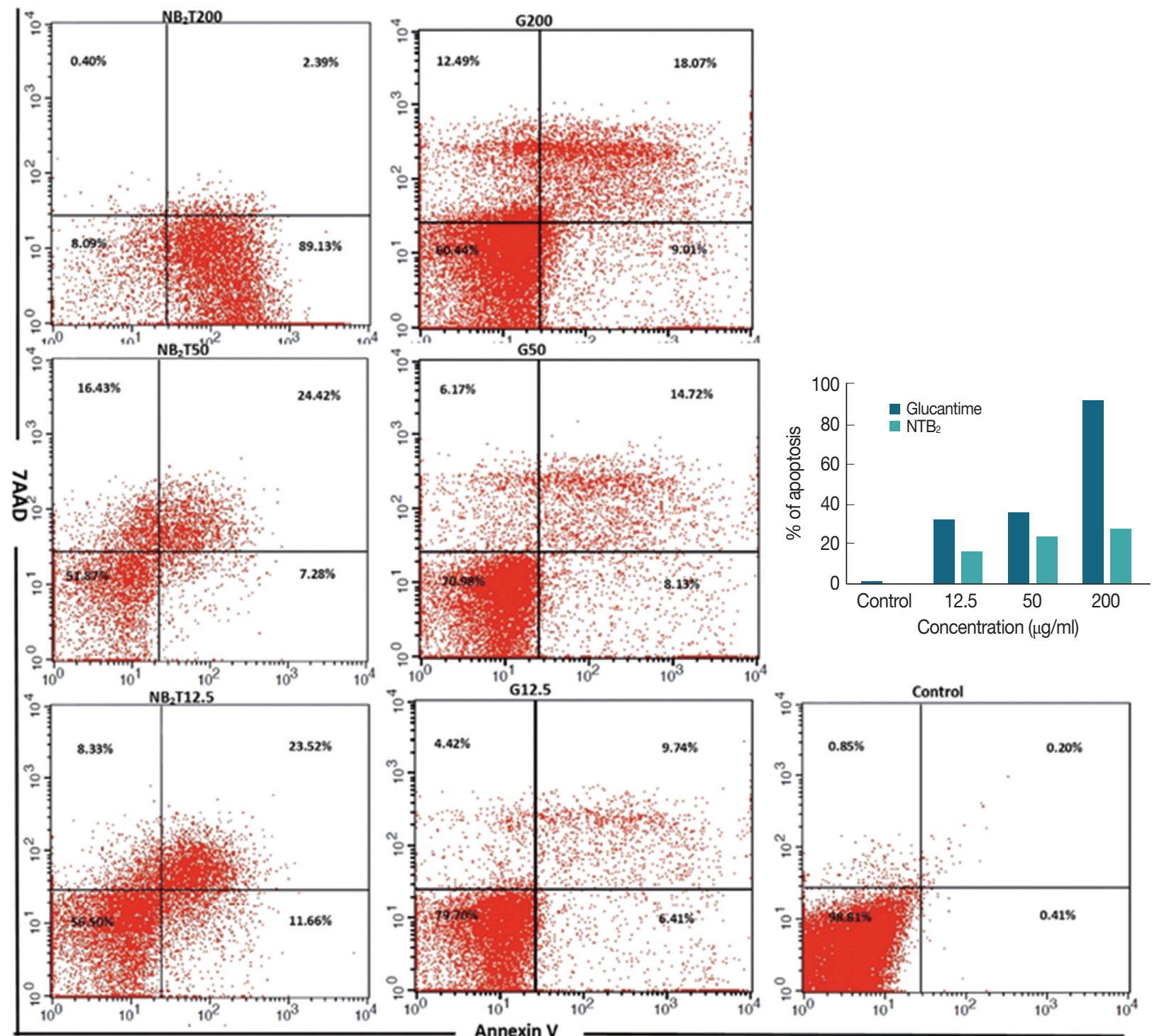

Fig. 7. The apoptotic and necrotic profiles of Leishmania tropica promastigotes treated with various concentrations of NTB 2 (serial dilutions were based on $\mathrm{NT}_{2}$ ) compared with positive and untreated control. 

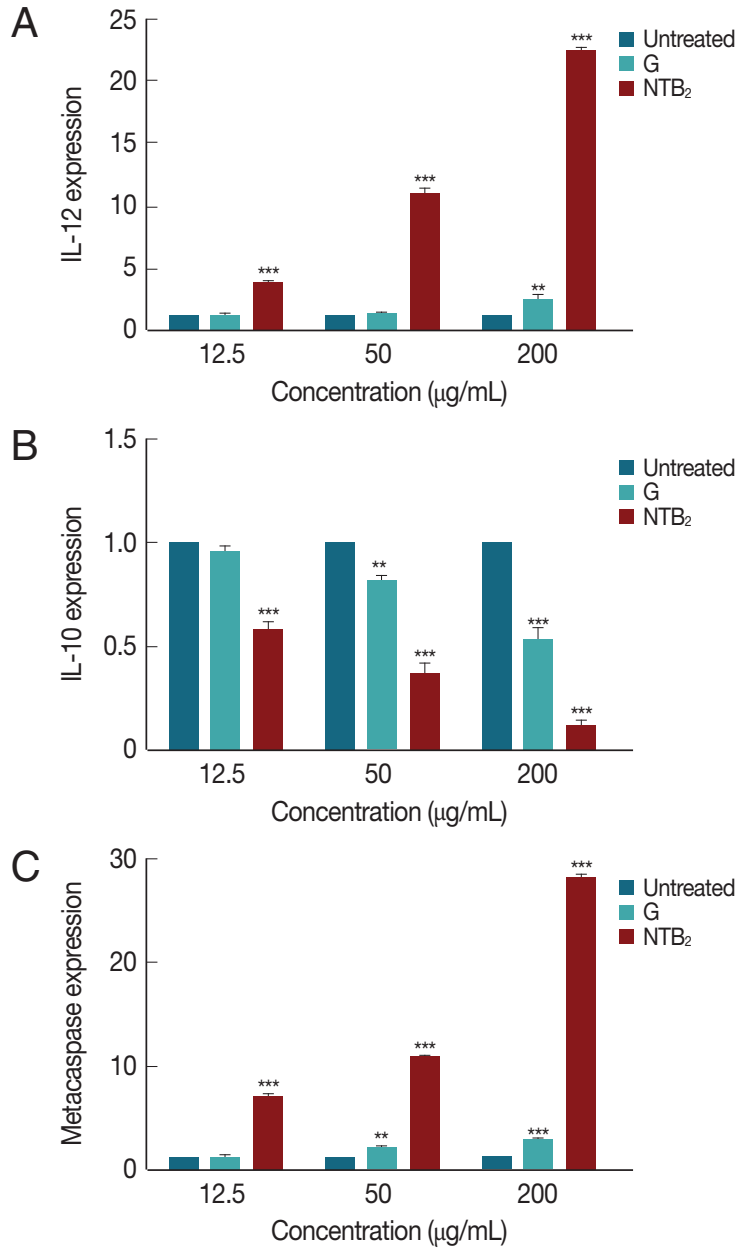

Fig. 8. Effect of different concentrations of $\mathrm{NTB}_{2}$ and positive control $(G)$ on genes expression of $(A) \| L-12$, (B) IL-10, and (C) metacaspase of $L$. tropica (NTB ${ }_{2}$ and $G$ compared to untreated control; $\left.{ }^{\star} P<0.05,{ }^{\star \star} P<0.01,{ }^{\star \star \star} P<0.001\right)$.

showed a significant reduction $(P<0.001)$ in the number of amastigotes compared to the untreated control group (Tables $2,3)$. Also, the mean number of amastigotes at different concentrations of niosomal formulations was significantly $(P<0.001)$ less than that of glucantime (Table 3$)$.

\section{Apoptosis}

The levels of apoptotic, necrotic, and viable cells at 3 different concentrations of the most effective combination of niosomal form $\left(\mathrm{NTB}_{2}\right)$ were determined and compared with the untreated and positive control (G) (Fig. 7). At the concentration of $200 \mu \mathrm{g} / \mathrm{ml}$ of niosomal combination of $\mathrm{NTB}_{2}$ formulation the best effect on the promastigote and amastigote stages, with a high rate of apoptosis $(89.13 \%$ early and $2.39 \%$ late apoptosis) was observed. However, the rates of induced apop- tosis in the $\mathrm{G}_{200}$ were $9.01 \%$ early and $18.07 \%$ late. Also, at the lower concentrations of this combination of niosome, a relatively high rate of apoptosis was observed $(31.7 \%$ \& $37.2 \%$ in $\mathrm{NTB}_{2} 50 \mu \mathrm{g} / \mathrm{ml}$ and $\mathrm{NTB}_{2} 12.5 \mu \mathrm{g} / \mathrm{ml}$, respectively).

\section{Gene expression}

The genes expression level of IL-12, IL-10, and metacaspase in response to $L$. tropica was evaluated against various concentrations of combination niosome $\mathrm{NTB}_{2}$ (Fig. 8). IL-12 expression in all the concentrations showed significant difference between untreated control and $\mathrm{NTB}_{2}(P<0.001)$, whilst glucantime only was significantly different with control at high concentrations $(200 \mu \mathrm{g} / \mathrm{ml})$. The difference between glucantime and $\mathrm{NTB}_{2}$ in all concentrations was significant $(P<0.001)$. In IL10 expression, a significant difference was observed in all concentrations between untreated control and $\mathrm{NTB}_{2}$ and G-treated organism $(P<0.001)$. Significant levels in metacaspase expression between these groups were also observed $(P<0.001)$.

\section{DISCUSSION}

Although CL is not a deadly disease it results in significant scars and facial disfigurements, thus being clinically important. In recent years, emergence of parasite resistance against the existing drugs has led to the introduction of newer chemotherapeutic agents and vesicular drug delivery systems such as niosomes [15]. In our another study, a clinical trial with the combination of tioxolone along with benzoxonium chloride for improvement of ACL carried out and showed that efficacy of this combination against $L$. tropica has been performed [6]. In present study, we performed several in vitro interactions of tioxolone along with benzoxonium chloride and its niosomal forms and their antileishmanial activities.

In our study, the niosomal forms of this compound were more effective than the simple form against $L$. tropica. The drug entrapment efficiency of niosomal forms was high and in vitro drugs release was gradual; however, benzoxonium chloride was entirely released within $90 \mathrm{~min}$, while tioxolone was released within $240 \mathrm{~min}$. The stability of the niosomal formulation of $\mathrm{NTB}_{2}$ was greater than $\mathrm{NTB}_{1}$ formulation and $\mathrm{NTB}_{2}$ formulation showed no significant change in the particle size after 6 months.

The combination of 2 drugs (tioxolone along with benzoxonium chloride) at higher concentrations, significantly showed a more pronounced leishmanicidal effect on the promastigote 
of $L$. tropica in comparison with single forms (T). Also, the inhibitory rate of promastigotes treated with tioxolone along with benzoxonium chloride compared with the gold standard drug (glucantime) was found to be significantly higher. This rate of promastigotes treated with various concentrations of the combination of niosomal forms showed that all formulations significantly exhibited high inhibitory effect in comparison with glucantime $(P<0.001)$. In fact, based on our findings, the simple and niosomal combination of these 2 drugs against promastigote of $L$. tropica were more effective than the standard drug. In the amastigote assays, in tioxolone along with benzoxonium chloride, at the highest concentration of each drug, the mean number of amastigote in each macrophage was $19.33 \pm 0.32$, while this number was lower in all of the niosomal formulations at the highest concentration.

In our study, in addition to the good anti-leishmanial effects of the niosomal forms of tioxolone along with benzoxonium chloride, these niosomes are significantly less toxic than glucantime. Also because $\mathrm{NTB}_{2}$ formulation demonstrated more physical stability, this formulation was preferably selected in this study.

Niosomal formulation of drugs have been demonstrated to be promising controlled drug delivery systems and niosomes also offer successful drug localization in skin with lower side effects, high stability, higher efficacy and cost-effective. Hence, many topical drugs may be developed using niosomal systems $[16,17]$. It has also been proven in our study that encapsulated drug in niosome reduces drug toxicity.

Apoptosis, a form of programmed cell death, has been described as genetically regulated physiological process of cell suicide. This phenomenon plays an important role in the immunopathogenesis of several parasitic diseases [18]. Apoptosis has already been reported in various unicellular organisms, including Leishmania, that this event has been reported in response to a wide range of stimuli, notably leishmanicidal drugs such as miltefosine [19], curcumin [20], pentamidine [21] and the molecule $\mathrm{H}_{2} \mathrm{O}_{2}$ [22].

Annexin $\mathrm{V}$ is a $35-36 \mathrm{kDa} \mathrm{Ca}^{2+}$ dependent phospholipidbinding protein, and binds to exposed apoptotic cell surface phospholipid. In Leishmania cells which lack any detectable levels of phosphatidylserine, a phospholipid that is exposed at the surface of metazoan cells in response to apoptotic stimuli, and Annexin $V$ binds other phospholipid classes such as phosphatidic acid, phosphatidylethanolamine; phosphatidylglycerol and phosphatidylinositol in Leishmania $[23,24]$. The trans- location of each of these phospholipids to the outer layer of the plasma membrane, one of the most characteristic features of apoptotic cell death, was observed in dead promastigotes. Our findings showed that on $\mathrm{NTB}_{2}$ treatment Leishmania promastigotes were able to bind to annexin $\mathrm{V}$ and induced a type of death that shared most of the features associated with higher number of early apoptotic event ( $89.13 \%$ in $200 \mu \mathrm{g} / \mathrm{ml}$ ), as the main mode of action [25].

Given the critical role of immune mediators in the pathogenesis and clinical outcome of $\mathrm{CL}$, it is plausible that functional polymorphisms in immune-related genes contribute to define the outcome of human infection [26]. IL-12 plays a crucial role in both natural and adaptive immunity of host against intracellular pathogens [27]. In our study, with an increase in the concentration of $\mathrm{NTB}_{2}$, the level of gene expression IL-12 increased significantly, that leads to increase the Th1 cytokine profile, which could make it potentially applicable for treatment of ACL. The expression of IL-12 at all 3 concentrations of $\mathrm{NTB}_{2}$ was significantly higher than $\mathrm{G}$; therefore, this drug is more effective than the first-line treatment of leishmaniasis (glucantime) in activating the immune system towards recovery, which represent an immunumodulatory mechanism against the leishmanial stages.

High levels of IL-10 production have been associated with active and chronic CL [22], because IL-10 in leishmaniasis has potent immunosuppressive effect on macrophage activation and has strong correlation with disease progression [28]. Our results showed significant reduction in IL-10 gene expression after treatment with $\mathrm{NTB}_{2}$, which is indicative of Th1 immune response enhancement and parasite death.

Metacaspases (MCAs) are caspase family cysteine peptidases that have been implicated in cell death processes in plants, fungi, and protozoa [29]. The MCA of L. major and L. donovani has been described as having a function in programming cellular death [29-31]. In this study, we showed that by increasing the concentration of the $\mathrm{NTB}_{2}$ drug in promastigotes of $L$. tropica, the expression of the MCA gene increases and lead immune responses towards host-protective Th1 response and contributes to apoptosis [32].

These findings indicated that the niosomal form of tioxolone along with benzoxonium chloride with less toxicity to glucantime demonstrated strong anti-leishmanial effects and was able to switch cell-mediated immunity towards recovery, could be promising for the treatment of ACL. The results also represented that tioxolone exhibited a potent lethal activity 
alone and more potent in combination. This synergistic effect induced the apoptotic pathways and also up regulation of an immunomodulatory role against as the main mode of action. Therefore, after successful in vitro evaluation of this niosomal formulation, complete international in vivo and clinical protocols should be carried out to introduce an effective topical niosomal drug for the treatment of ACL.

\section{ACKNOWLEDGMENTS}

This project (protocol no. 94/655) was granted approval by the Leishmaniasis Research Center and received financial support from the Vice Chancellor for Research at the Kerman University of Medical Sciences. This study is a part of a Ph.D dissertation for pursuit of a Ph.D by Research degree in leishmaniasis and skin diseases.

\section{CONFLICT OF INTEREST}

The authors declare that there are no conflicts of interest.

\section{REFRENCES}

1. Cortez de Sá J, Almeida-Souza F, Mondêgo-Oliveira R, Oliveira Idos S, Lamarck L, Magalhães Ide F, Ataídes-Lima AF, Ferreira Hda S, Abreu-Silva AL. Leishmanicidal, cytotoxicity and wound healing potential of Arrabidaea chica Verlot. BMC Complement Altern Med 2016; 16: 1.

2. de Vries HJ, Reedijk SH, Schallig HD. Cutaneous leishmaniasis: recent developments in diagnosis and management. Am J Clin Dermatol 2015; 16: 99-109.

3. Plano D, Baquedano Y, Moreno-Mateos D, Font M, JiménezRuiz A, Palop JA, Sanmartín C. Selenocyanates and diselenides: a new class of potent antileishmanial agents. Eur J Med Chem 2011; 46: 3315-3323.

4. Sharifi F, Sharifi I, Zarean M, Parizi MH, Aflatoonian M, Harandi MF, Zahmatkesh R, Mashayekhi M, Kermanizadeh A. Spatial distribution and molecular identification of Leishmania species from endemic foci of south-eastern Iran. Iran J Parasitol 2012; 7: 45-52.

5. Kazi KM, Mandal AS, Biswas N, Guha A, Chatterjee S, Behera M,Kuotsu K. Niosome: a future of targeted drug delivery systems. J Adv Pharm Technol Res 2010; 1: 374-380.

6. Daie Parizi MH, Karvar M, Sharifi I, Bahrampour A, Heshmat Khah A, Rahnama Z,Baziar Z, Amiri R. The topical treatment of anthroponotic cutaneous leishmaniasis with the tincture of thioxolone plus benzoxonium chloride (Thio-Ben) along with cryotherapy: A single-blind randomized clinical trial. Dermatol Ther 2015; 28: 140-146.
7. Kim JE, Kim HS, Shin YJ, Lee CS, Won CH, Lee SA, Lee JW, Kim YS, Kang JS, Ye SK, Chung MH. LYR71, a derivative of trimeric resveratrol, inhibits tumorigenesis by blocking STAT3-mediated matrix metalloproteinase 9 expression. Exp Mol Med 2008; 40: 514-522.

8. Kim BH, Roh E, Lee HY, Lee IJ, Ahn B, Jung SH, Lee H, Han SB, Kim Y. Benzoxathiole derivative blocks lipopolysaccharide-induced nuclear factor-kappaB activation and nuclear factor-kappaB-regulated gene transcription through inactivating inhibitory kappaB kinase beta. Mol Pharmacol 2008; 73: 1309-1318.

9. Kim BH, Min YS, Choi JS, Baeg GH, Kim Y, Shin JW, Kim TY, Ye SK. Benzoxathiol derivative BOT-4-one suppresses L540 lymphoma cell survival and proliferation via inhibition of JAK3/ STAT3 signaling. Exp Mol Med 2011; 43: 313-321.

10. Pardakhty A, Shakibaie M, Daneshvar H, Khamesipour A, Mohammadi-Khorsand T, Forootanfar H. Preparation and evaluation of niosomes containing autoclaved Leishmania major: a preliminary study. J Microencapsul 2012; 29: 219-224.

11. Attia IA, El-Gizawy SA, Fouda MA, Donia AM. Influence of a niosomal formulation on the oral bioavailability of acyclovir in rabbits. AAPS Pharm Sci Tech 2007; 8: 206-212.

12. Shahiwala A, Misra A. Studies in topical application of niosomally entrapped Nimesulide. J Pharm Pharm Sci 2002; 5: 220-225.

13. Chandra D, Naik S. Leishmania donovani infection down-regulates TLR2-stimulated IL-12p40 and activates IL-10 in cells of macrophage/monocytic lineage by modulating MAPK pathways through a contact-dependent mechanism. Clin Exp Immunol 2008; 154: 224-234.

14. Satheesh Kumar S, Gokulasuriyan RK, Ghosh M. Comparative in-silico genome analysis of Leishmania (Leishmania) donovani: a step towards its species specificity. Meta Gene 2014; 2: 782-798.

15. Yasinzai M, Khan M, Nadhman A, Shahnaz G. Drug resistance in leishmaniasis: current drug-delivery systems and future perspectives. Future Med Chem 2013; 5: 1877-1888.

16. Rahimpour Y, Hamishehkar H. Niosomes as carrier in dermal drug delivery. Recent Advances in Novel Drug Carrier Systems 2012; 1: 141-164.

17. Yasam VR, Jakki SL, Natarajan J, Kuppusamy G. A review on novel vesicular drug delivery: proniosomes. Drug Deliv 2014; 21: 243-249.

18. Barcinski MA, DosReis GA. Apoptosis in parasites and parasiteinduced apoptosis in the host immune system: a new approach to parasitic diseases. Braz J Med Biol Res 1999; 32: 395-401.

19. Paris C, Loiseau PM, Bories C, Bréard J. Miltefosine induces apoptosis-like death in Leishmania donovani promastigotes. Antimicrob Agents Chemother 2004; 48: 852-859.

20. Das R, Roy A, Dutta N, Majumder HK. Reactive oxygen species and imbalance of calcium homeostasis contributes to curcumin induced programmed cell death in Leishmania donovani. Apoptosis 2008; 13: 867-882.

21. Nguewa PA, Fuertes MA, Cepeda V, Iborra S, Carrión J, Valladares B, Alonso C, Pérez JM. Pentamidine is an antiparasitic 
and apoptotic drug that selectively modifies ubiquitin. Chem Biodivers 2005; 2: 1387-1400.

22. Das M, Mukherjee SB, Shaha C. Hydrogen peroxide induces apoptosis-like death in Leishmania donovani promastigotes. J Cell Sci 2001; 114: 2461-2469.

23. Weingärtner A, Kemmer G, Müller FD, Zampieri RA, Gonzaga dos Santos M, Schiller J, Pomorski TG. Leishmania promastigotes lack phosphatidylserine but bind annexin $\mathrm{V}$ upon permeabilization or miltefosine treatment. PLoS One 2012; 7: e42070.

24. Basmaciyan L, Azas N, Casanova M. Calcein+/PI- as an early apoptotic feature in Leishmania. PLoS One 2017; 12: e0187756.

25. Hingorani R, Deng J, Elia J, Mcintyre C, Mittar D. Detection of Apoptosis Using the BD Annexin V FITC Assay on the BD FACSVerse $^{\mathrm{TM}}$ System. San Jose, USA. BD Biosciences 2011, pp 1-12.

26. Mera-Ramírez A, Castillo A, Orobio Y, Gómez MA, GallegoMarin C. Screening of TNFa, IL-10 and TLR4 single nucleotide polymorphisms in individuals with asymptomatic and chronic cutaneous leishmaniasis in Colombia: a pilot study. BMC Infect Dis 2017; 17: 177.

27. Martorelli D, Muraro E, Merlo A, Turrini R, Fae DA, Rosato A,
Dolcetti R. Exploiting the interplay between innate and adaptive immunity to improve immunotherapeutic strategies for EpsteinBarr-virus-driven disorders. Clin Dev Immunol 2012; 3: 931952.

28. Bogdan C, Vodovotz Y, Nathan C. Macrophage deactivation by interleukln 10. J Exp Med 1991; 174: 3-7.

29. Ambit A, Fasel N, Coombs GH, Mottram JC. An essential role for the Leishmania major metacaspase in cell cycle progression. Cell Death Differ 2008; 15: 113-122.

30. González IJ, Desponds C, Schaff C, Mottram JC, Fasel N. Leishmania major metacaspase can replace yeast metacaspase in programmed cell death and has arginine-specific cysteine peptidase activity. Int J Parasitol 2007; 37: 161-172.

31. Lee N, Gannavaram S, Selvapandiyan A, Debrabant A. Characterization of metacaspases with trypsin-like activity and their putative role in programmed cell death in the protozoan parasite Leishmania. Eukaryot Cell 2007; 6: 1745-1757.

32. Debrabant A, Lee N, Bertholet S, Duncan R, Nakhasi HL. Programmed cell death in trypanosomatids and other unicellular organisms. Int J Parasitol 2003; 33: 257-267. 